\title{
DO SIBERIAN FLYING SQUIRRELS REUSE NEST MATERIALS MADE BY OTHER INDIVIDUALS?
}

\author{
Tatsuo Oshida*, Aika Комoto, Minori Shibatani, Yuta Yoshikawa and Daisuke Sato \\ Laboratory of Wildlife Biology, Obihiro University of Agriculture and Veterinary Medicine \\ Inada, Obihiro 080-8555, Japan; *E-mail address: oshidata@obihiro.ac.jp
}

\begin{abstract}
Arboreal small mammals nesting in tree hollows usually line nests with materials such as leaves and shredded bark. Pteromys volans orii (Siberian flying squirrel), an endemic subspecies to Hokkaido, Japan, uses shredded bark. Since their nest materials have a very consistent shape, we suspect the squirrels use much effort to collect and shred the bark. To save effort, they may reuse nest materials made by other individuals. To test this, we mixed artificial nest materials (coloured cotton strings) into nest materials and observed the transfer of strings among nests. Of 39 nest boxes seeded with coloured cotton strings, number of strings decreased in 25 boxes (64.10\%). Strings from 12 boxes were moved to other boxes. In addition, we found that $P$. volans orii possibly reused nest materials prepared by other individuals. Both nests and nest materials may be important re-useable resources for $P$. volans orii.
\end{abstract}

Keywords: Japan, nest box, Pteromys volans orii, reusable resource, shredded bark.

\section{INTRODUCTION}

Arboreal small mammals nesting in tree hollows usually carry nest materials such as leaves and bark to their cavities (e.g. Gurnell 1987, ANdo 2005, Thorington \& FerRell 2006). Cavity nests of northern flying squirrels, Glaucomys sabrinus are lined with shredded bark, moss, lichen and leaves (WellsGosling \& Heaney 1984, Paterson et al. 2008). Southern flying squirrels, G. volans, most often line nests with shredded bark, although moss, lichen, feathers and leaves can be used (Dolan \& CARTER 1977). Small Japanese field mice, Apodemus argenteus bring many leaves into their nests (ANDo 2005). Japanese giant flying squirrels, Petaurista leucogenys (ANDo \& SHIRAIshi 1983) and Japanese flying squirrels, Pteromys momonga (ANDo 2005) mainly use bark shredded from Cryptomeria japonica. Japanese dormice, Glirulus japonicus collect bark of $C$. japonica and leaves (ANDo 2005). Hylopetes sp. in tropical rainforest in Vietnam also uses leaves (Kато et al. 2011). The function of nest materials is not clearly resolved, but these materials would play important roles for resting and reproduction of arboreal small mammals.

Pteromys volans orii (Linnaeus, 1758) (Siberian flying squirrel), an endemic subspecies to Hokkaido, Japan, also uses nest materials in cavity nests (e.g. Oshida 2015). These materials are mainly bark of vines, such as Vitis coignetiae 
(YanAGawa 1999). The squirrels cut very narrow pieces of bark to fill their nests (Fig. 1a). We suspect these squirrels allocate much effort to collect and shred bark. Many arboreal squirrel species, such as Japanese squirrel, Sciurus lis (TAmura 2015a) and Pallas's squirrel, Callosciurus erythraeus (Tamura 2015b) collect nest materials (bark and twigs) for building their dreys on tree branches. To build their dreys, Sciurus and Callosciurus squirrels also shred bark (e.g. Gurnell 1987, Ci 2008, TAmura 2015a), but each shredded piece is not as narrow or standardized in shapes as those (Fig. 1a) made by P. volans orii.

Pteromys volans orii rarely builds dreys on tree branches; they usually use cavity nests (e.g. Oshida 2015). They produce a very specific shape of nest material (Fig. 1a). To save energy costs of preparing nest materials, these squirrels may reuse nest materials made by other individuals. Home ranges of male P. volans orii overlap those of females and other males (e.g. YANAGAWA 1999), although females are territorial. Therefore, some squirrels have the opportunity to reuse nest materials made by other squirrels. To test this conjecture, we mixed artificial nest materials (coloured cotton strings) into original nest materials and documented the transfer of coloured strings among nests. When artificial nest materials provided initially for one flying squirrel were used by other flying squirrel individuals, we would consider nest materials to be reusable resource. We here discuss the utilization of nest materials among $P$. volans orii individuals.

\section{MATERIAL AND METHODS}

\section{Study sites}

This study was conducted in the University of Tokyo Hokkaido Forest, Furano, Hokkaido, Japan $\left(43^{\circ} 10-20^{\prime} \mathrm{N}, 142^{\circ} 18-40^{\prime} \mathrm{E}\right)$. This forest has an area of 22,717 ha. It is charac-
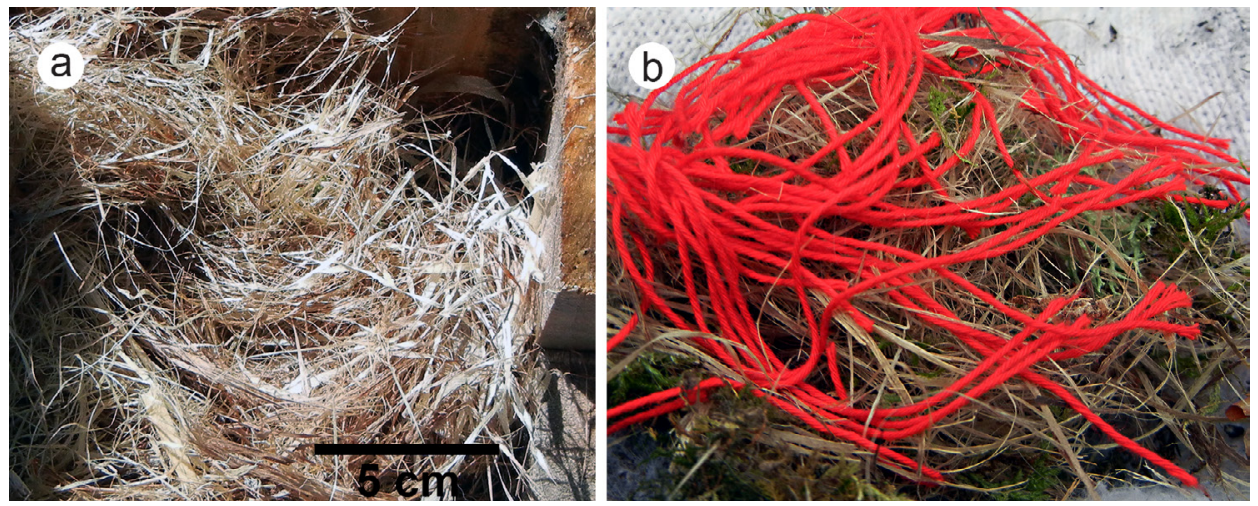

Fig. 1. a) Nest box with nest materials made by Pteromys volans orii; b) coloured cotton strings mixed with original nest materials of $P$. volans orii 
terized by natural sub-arctic mixed forests. Dominant stands are Abies sachalinensis, Tilia japonica, Acer mono and Picea jezoensis (Үамамото et al. 1995). In this forest, we established two study sites (A and B). The site A is about $6 \mathrm{~km}$ away from the site B. Each site was 5.4 ha area at about $600 \mathrm{~m}$ above sea level with similar vegetation dominated by Abies sachalinensis.

\section{Pre-examination}

Following to Suzuki et al. (2011), we built wooden nest boxes with inside dimensions of $11 \mathrm{~cm}$ by $16 \mathrm{~cm}$ by $20 \mathrm{~cm}$. Entrance dimensions were $4 \mathrm{~cm}$ by $4 \mathrm{~cm}$. In May 2011, in each study site, we attached 60 nest boxes to trees at heights of $3 \mathrm{~m}$. Following Suzuki et al. (2011), we made three line transects, placing 20 nest boxes along each transect at 20-30-m intervals (Fig. 2). Distances between lines were around $30 \mathrm{~m}$. Nest boxes were numbered from 1 to 60 for each study site and named A1 to A60 and B1 to B60 in sites A and B, respectively. Each month, from May to October 2012, in the daytime, we checked inside all nest boxes. When we found nest materials in a nest box, we collected part (around 50 pieces of shredded bark) as a sample. Nest materials found in nest boxes in May 2012 were considered to be prepared by P. volans orii from May 2011 to April 2012.

From each sample from each nest, we randomly choose 30 pieces of shredded bark. After drying, we pasted the pieces onto drafting paper. We measured length and width of each piece to nearest $0.01 \mathrm{~mm}$ by digital caliper. Width was measured from three different parts of each piece and averaged. In site A, the means ( \pm standard deviation) of lengths and widths of nest materials from May 2011 to April 2012 were $84.63 \pm 33.40 \mathrm{~mm}$ and $0.79 \pm 0.48$ $\mathrm{mm}$, respectively. Means of lengths and widths of materials from May to October 2012 were $98.33 \pm 36.98 \mathrm{~mm}$ and $1.25 \pm 1.26 \mathrm{~mm}$, respectively. In site $\mathrm{B}$, means of lengths and widths of materials from May 2011 to April 2012 were $69.84 \pm 23.85 \mathrm{~mm}$ and $0.74 \pm 0.47 \mathrm{~mm}$, respectively. Means of lengths and widths from May to October 2012 were 100.37 \pm 38.53 $\mathrm{mm}$ and $0.95 \pm 0.77 \mathrm{~mm}$, respectively. Based on these measurement data, we prepared the artificial nest materials (coloured cotton strings, Fig. $1 b$ ) to mix into the original nest materials. Lengths of these strings were $90.00 \mathrm{~mm}$ (site A) and $85.00 \mathrm{~mm}$ (site B). Widths were $1.00-1.50 \mathrm{~mm}$. To clearly distinguish each sample, we prepared a different colour of cotton strings for each nest.
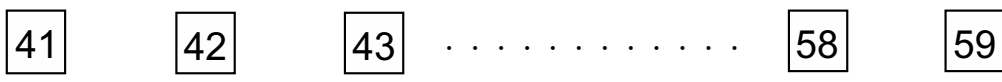

60
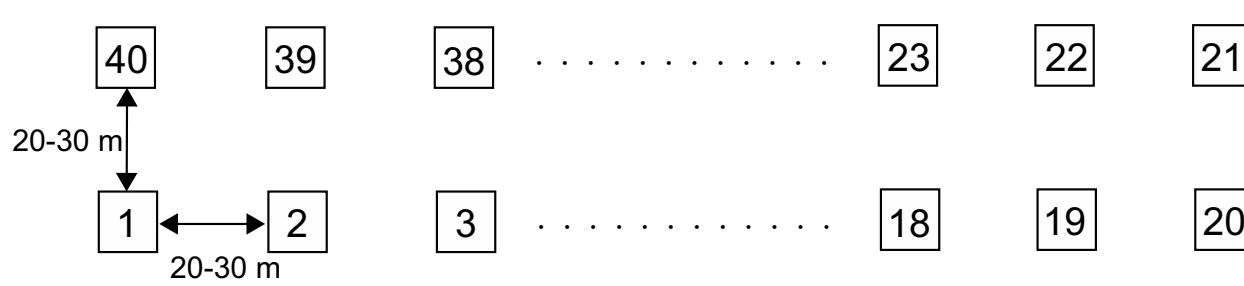

Fig. 2. Sixty numbered nest boxes (open squares and dots) were attached to trees at heights of $3 \mathrm{~m}$. We made three line transects, placing 20 nest boxes along each transect at $20-30 \mathrm{~m}$ intervals 


\section{Examination in reuse of nest materials}

All nest boxes stayed on tree trunks for 2013 and 2014. Each month, from May to September in 2013 and from May to October in 2014, we checked inside each nest box in the daytime. When we found flying squirrels in nest boxes, to distinguish each individual, we ear-tagged them (Suzuki et al. 2011). Ear tags were $2.5 \mathrm{~mm}$ by $6.0 \mathrm{~mm}$ (KN-295-A, Natsume Seisakushyo Co., Ltd). In each year, when we first found nest materials in nest box, we mixed coloured cotton strings into nest materials. The number of coloured cotton strings mixed in each nest box was 50. We prepared 15 different coloured cotton strings: black, blue, brown, green, light blue, light brown, light green, light purple, orange, pink, purple, red, vermilion, white and yellow. Cotton strings mixed into nest materials of each nest box were initially different in colour. Due to the limited number of colours, we sometimes repeated a colour in 2014. In these cases, we tied the knots at both ends of each string to distinguish strings of 2014 from those of 2013. In site A, we added strings to 11 and 7 nest boxes in 2013 and 2014, respectively. In site B, we added them to 12 and 9 nest boxes in 2013 and 2014, respectively. When we found strings in a nest box, we recorded colour and one of the seven possible cases shown in Fig. 4. Cases 2, 3, 4 and 5 suggest that $P$. volans orii reuse nest materials made by other individuals. Cases 6 and 7 may suggest that they reuse own nest materials. To confirm whether the similar tendency on use of nest materials is found between two separated forests, we compared the observed cases between sites A and $\mathrm{B}$ with Fisher's exact test. When we found strings in a different nest box, we measured straight-line distance from original nest box to new nest box.

\section{RESULTS}

In site A, we identified 11 adult flying squirrels: 7 males (nos 11, 32, 33, 34, 35, 38 and 276) and 4 females (nos 3, 27, 30 and 31) and 8 adults: 3 males (nos. 47, 51 and 58) and 3 females (nos 43, 46 and 57) in 2013 and 2014, respectively. In site B, we identified 5 adults: 2 males (nos 20 and 29) and 3 females (nos 28, 36 and 37) and 6 adults: 1 male (no. 42) and 5 females (nos 40, 41, 44, 45 and 48) in 2013 and 2014, respectively.

In sites $A$ and $B$, number of strings decreased in 12 of 18 nests and 13 of 21 nests, respectively. In total, strings decreased in $64.10 \%$ of nests. Between the two sites, there was no significant difference in number of nest boxes that lost strings $(P=1.0)$. Strings from three and nine nests were moved from original nest boxes to other nest boxes in 2013 and 2014, respectively. Distances of string movements were $52.09 \pm 15.36 \mathrm{~m}$ and $62.92 \pm 35.51 \mathrm{~m}$ in sites A and B, respectively.

Of the possible cases in Fig. 3, we did not find examples of cases 1, 2 and 6. We observed case 3 once: light blue strings placed in nest box B2 in July 2013 were found in nest box B34 in May 2014. The B2 had been used by female no. 36 in July 2013, but B34 was used by female no. 41. Case 4 was found four times: coloured strings in nest boxes A3, A7, A43 and A56 were initially used by female no. 27 , male no. 34 , female no. 30 and female no. 3, respectively. Later, these strings and nest boxes were used by male no. 33 , male no. 47 , fe- 
male no. 57 and male no. 58, respectively. Case 5 was observed four times: 1) female no. 28 initially used nest box B13 with red strings, but used B32 with brown strings two months later; 2) male no. 42 initially used B41 with white

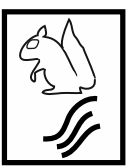

We initially set the materials for this individual in this box.

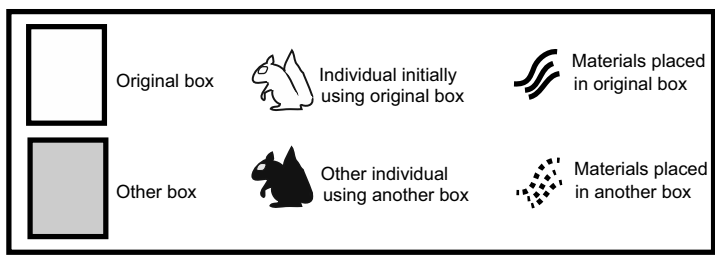

Case number

Possible cases

This individual used materials in this box

2

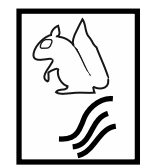
1

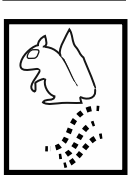

3

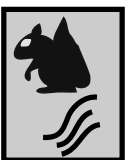

This individual used different materials in this box

Different individual used materials in the different box

4

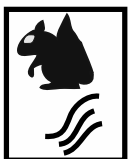

Different individual used materials in this box

5

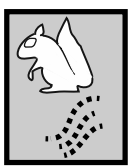

This individual used different materials in different box

6

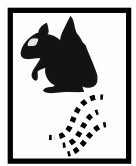

7

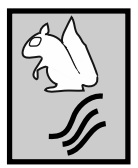

Different individual used different materials in this box
Explanation

Interpretation

This individual used the materials in this box

Conservative use

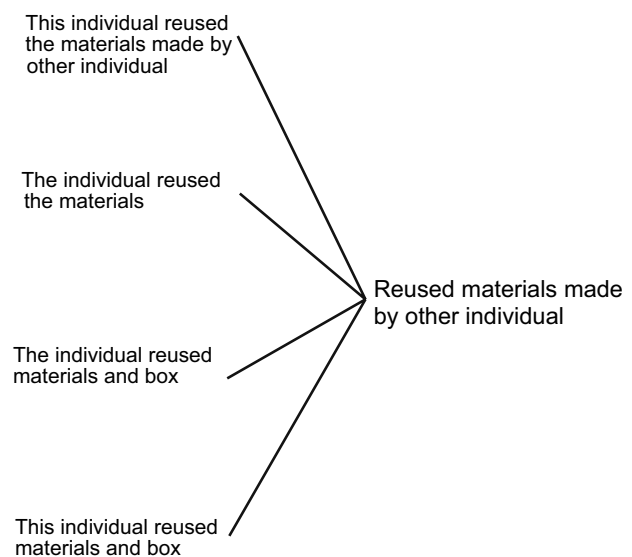

This individual used the different materials in the different box

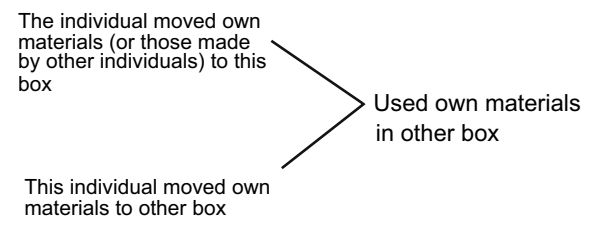

Fig. 3. Possible behavioral cases (1-7) for use of nest box and nest materials by Pteromys volans orii individuals 
strings, but used B33 with blue strings one month later; 3) female no. 48 initially used B14 with orange strings and then moved to B26 which had black strings; and 4) female no. 45 initially used B57 with purple strings added in 2014, but one month later was using B45 with purple strings added in 2013. Case 7 was observed once: female no. 45 initially used purple strings in B57 and, one month later, used those purple strings in B54. Therefore, $P$. volans orii used nest materials made by other individuals four times in site $\mathrm{A}$ and five times in site B. Between two sites, there was no significant difference in number of cases reused strings $(P=1.0)$.

\section{DISCUSSION}

As there were no significant differences in number of nest boxes that lost strings and in number of cases reused strings between two study sites, the patterns to use nest materials may be common among $P$. volans orii. Since the cases 3, 4 and 5 (Fig. 3) were observed, $P$. volans orii potentially reuses nest materials prepared by other individuals. Case 7 (Fig. 3) shows that, when moving, $P$. volans orii also carries nest materials to other nest boxes. Each $P$. volans orii individual usually has several nests in its home range and frequently moves nest materials among nests (AsAri et al. 2008).

In southern Finland, average $P$. volans home range size was 59.9 ha for males and 8.3 ha for females; average distance moved from the nest at night was $292 \mathrm{~m}$ for males and $111 \mathrm{~m}$ for females (HANski et al. 2000). Home range sizes of male and female $P$. volans orii are 2.2 ha and 1.7 ha, respectively (YANAGAwA 1999). In the present study, coloured cotton strings were moved $52.09 \pm 15.36 \mathrm{~m}$ and $62.92 \pm 35.51 \mathrm{~m}$ in sites A and B, respectively. Although these distances between nest boxes are short enough to be within one squirrel's home range, we observed different individuals using both nests and materials. Unfortunately, we were not able to identify which individual moved the materials. Future study should identify how and which individuals move materials, possibly by automatic cameras or a tracking system, such as radiotelemetry.

Like arboreal squirrels, arboreal great apes such as orangutans (Pongo pygmaeus and P. abelii) (e.g. Kuze et al. 2011, van Casteren et al. 2012) and common chimpanzees, Pan troglodytes (e.g. Koops et al. 2012, SAmson 2012) build nests (or sleeping platforms) using leaves and branches on branches. In general, each great ape builds a new nest each night. After use, the nests are usually discarded, although reuse of nests is occasionally observed. Therefore, their nests seem to be a disposable resource. For arboreal squirrels such as $G$. volans and $P$. volans orii, however, nests are generally maintained for certain periods in the home range (e.g. WeLls-GosLing 1985). Unlike the nests of 
great apes, nest resources such as cavities for arboreal squirrels are restricted in a forest habitat, making them unlikely to be disposable. When $P$. volans orii find a nest resource, such as cavity or nest box previously used by other individuals, they may use nest materials collected by other individuals. Both nests and nest materials may be important re-useable resources for $P$. volans orii.

Acknowledgements - We are grateful to T. Akasaka, M. Takada and H. Yanagawa for their critical comments on our study. We thank A. Ohkawa, K. Iguchi and A. Sanyoshi of the University of Tokyo Hokkaido Forest for their cooperation in the field. We thank all members of Laboratory of Wildlife Biology, Obihiro University of Agriculture and Veterinary Medicine for their kind help in the field. We thank C. L. Bridgman for her critical reading of our manuscript.

\section{REFERENCES}

Ando, M. (2005): Improvement of nest box investigation techniques for study of arboreal rodents. - Honyuruikagaku (Mammalian Science) 45:165-176. [in Japanese with an English abstract]

Ando, M. \& Shiraishi, S. (1983): The nest and nest-building behavior of the Japanese giant flying squirrel, Petaurista leucogenys. - Science Bulletin of the Faculty of Agriculture, Kyushu University 2-3: 59-69. [in Japanese with English abstract]

Asari, Y., Tojo, R. \& Yanagawa, H. (2008): The distances among nests used by the Siberian flying squirrel in different habitats. - Animate 7: 40-43. [in Japanese with an English abstract]

van Casteren, A., Sellers, W. I., Thorpe, S. K. S., Coward, S., Crompton, R. H., Myatt, J. P. \& ENNos, A. R. (2012): Nest building orangutans demonstrate engineering knowhow to produce safe, comfortable beds. - Proceedings of the National Academy Sciences 18: 6873-6877. https://doi.org/10.1073/pnas.1200902109

CI, W-L. (2008): A field guide to mammals in Taiwan. - Big Tree Culture Ltd. Inc., Taipei, 255 pp. [in Chinese]

Dolan, P. G. \& Carter, D. C. (1977): Glaucomys volans. - Mammalian Species 78: 1-4. https://doi.org/10.2307/3504026

Gurnell, J. (1987): The natural history of squirrels. - Christopher Helm, London, 201 pp.

Hanski, I. K., Stevens, P., Ihalempï̈, P. \& Selonen, V. (2000): Home-range size, movements, and nest site use in the Siberian flying squirrel, Pteromys volans. - Journal of Mammalogy 81: 798-809. https://doi.org/10.1644/1545-1542(2000)081<0798:HRSMAN>2.3.CO;2

Kato, A., Oshida, T., Nguyen, S. T., Nguyen, N. X., Luon, H. V., HA, T. V., Truong, B. Q., ENDo, H. \& NGuYen, D. X. (2011): Nest box utility for arboreal small mammals in Vietnam's tropical forest. - Russian Journal of Theriology 10: 59-64. https://doi. org/10.15298/rusjtheriol.10.2.03

Koops, K., McGrew, W. C., de Vries, H. \& Matsuzawa, T. (2012): Nest building by chimpanzees (Pan troglodytes verus) at Seringbara, Nimba Mountains: antipredation, thermoregulation, and antivestor hypotheses. - International Journal of Primatology 33: 356-380. https://doi.org/10.1007/s10764-012-9585-4 
Kuze, N., Kawabata, H., Yamazaki, S., Kanamori, T., Malim, T. P. \& Bernard, H. (2011): A wild Borneo orangutan carries large numbers of branches on the neck for feeding and nest building in the Danum Valley Conservation Area. - Primate Research 27: 21-26. https://doi.org/10.2354/psj.27.007

Oshida, T. (2015): Pteromys volans (Linnaeus, 1758). Pp. 196-197. In: ОндAchi, S. D., Ishibashi, Y., IwasA, M. A., Fukui, D. \& SAitoh, T. (eds): The wild mammals of Japan, 2nd edition. - Shoukadoh Book Sellers, Kyoto, Japan.

Patterson, J. E. H., Patterson, S. J. \& Malcolm, J. R. (2008): Cavity nest materials of northern flying squirrels, Glaucomys sabrinus, and north American red squirrels, Tamiasciurus hudsonicus, in a secondary forest of southern Ontario. - The Canadian FieldNaturalist 121: 303-307. https://doi.org/10.22621/cfn.v121i3.479

SAmson, D. R. (2012): The chimpanzee nest quantified: morphology and ecology of arboreal sleeping platforms within the dry habitat site of Toro-Semliki Wildlife Reserve, Uganda. - Primates 53: 357-364. https://doi.org/10.1007/s10329-012-0310-x

Suzuki, M., Kato, A., Matsui, M., Okahira, T., Iguchi, K., Hayashi, Y. \& Oshida, T. (2011): Preliminary estimation of population density of the Siberian flying squirrel Pteromys volans orii in natural forest of Hokkaido, Japan. - Mammal Study 36: 155-158. https:// doi.org/10.3106/041.036.0306

Tamura, N. (2015a): Sciurus lis Temminck, 1844. Pp. 192-194. In: Оhdachi, S. D., Ishibashi, Y., Iwasa, M. A., Fukui, D. \& SAItoh T. (eds): The wild mammals of Japan, 2nd edition. Shoukadoh Book Sellers, Kyoto, Japan.

Tamura, N. (2015b): Callosciurus erythraeus (Pallas, 1779). Pp. 196-197. In: Ohdachi, S. D., Ishibashi, Y., Iwasa, M. A., Fukui, D. \& Saitoh T. (eds): The wild mammals of Japan, 2nd edition. - Shoukadoh Book Sellers, Kyoto, Japan.

Thorington, R. W. \& Ferrell, K. E. (2006): Squirrels: the animal answer guide. - The Johns Hopkins University Press, Baltimore, Maryland, 183 pp.

Wells-Gosling, N. \& Heaney, L. R. (1984): Glaucomys sabrinus. - Mammalian Species 229: $1-8$.

Wells-Gosling, N. (1985): Flying squirrels: glider on the dark. - Smithsonian Institution Press, USA, 128 pp. https://doi.org/10.2307/3503926

Yamamoto, H., Nitami, T. \& Kisanuki, H. (1995): Stand structure of mixed-species stands (I) Relation of species composition and topographic factors. - Journal of the Japanese Forest Society 77: 47-54. [in Japanese with English abstract]

YANAGAwA, Y. (1999): Ecological note on the Russian flying squirrel (Pteromys volans orii) with a video camera. - Honyuruikagaku (Mammalian Science) 39: 181-183. [in Japanese]

Received March 20, 2017, accepted August 9, 2017, published May 31, 2018 